\title{
Enhanced whale optimization algorithm for active power loss diminution
}

\author{
Lenin Kanagasabai \\ Department of EEE, Prasad V. Potluri Siddhartha Institute of Technology, India
}

\begin{tabular}{|c|c|}
\hline Article Info & ABSTRACT \\
\hline Article history: & In this paper Enhanced whale Optimization Algorithm (EWO) proposed to \\
\hline Received Nov 8, 2019 & $\begin{array}{l}\text { solve the optimal reactive power problem. Whale optimization algorithm is } \\
\text { modeled by Bubble-net hunting tactic. In the projected optimization }\end{array}$ \\
\hline Revised Nov 15, 2019 & algorithm an inertia weight $\omega \in[1,0]$ has been introduced to perk up the \\
\hline Accepted Jan 12, 2020 & $\begin{array}{l}\text { search ability. Whales are commonly moving } 10-16 \text { meters down then } \\
\text { through the bubbles which are created artificially then they encircle the prey }\end{array}$ \\
\hline Keywords: & $\begin{array}{l}\text { and move upward towards the surface of sea. Proposed Enhanced whale } \\
\text { optimization algorithm (EWO) is tested in standard IEEE } 57 \text { bus systems and }\end{array}$ \\
\hline Optimal reactive power & \\
\hline
\end{tabular}

Transmission loss

Whale optimization algorithm

This is an open access article under the CC BY-SA license.

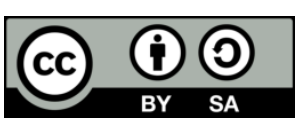

\section{Corresponding Author:}

Lenin Kanagasabai,

Department of EEE,

Prasad V. Potluri Siddhartha Institute of Technology,

Chalasani Nagar, Kanuru, Vijayawada, Andhra Pradesh 520007, India.

Email: gklenin@gmail.com

\section{INTRODUCTION}

In this work minimization of real power loss is key goal. A variety of conventional techniques has been already solved the problem [1-6] but many techniques underwent complexity in managing the in-equality constraints. Subsequently evolutionary techniques [7-15] have been successfully solved the problem. In this work Enhanced whale Optimization Algorithm (EWO) is applied to solve the optimal reactive power problem. Whale algorithm modelled by Bubble-net hunting strategy of whale [16] and with respect to current excellent candidate, solution will be obtained. Alike to Particle Swarm Optimization algorithm, an inertia weight; $\omega \in$ $[1,0]$ is introduced into whale optimization algorithm to augment the search and called as Enhanced whale optimization algorithm. Projected EWO algorithm evaluated in standard IEEE 57 bus systems and power loss has been reduced powerfully.

\section{PROBLEM FORMULATION}

Reduction real power loss is the key goal of this work and it has been written as follows:

$$
\begin{aligned}
& F=P_{L}=\sum_{k \in N b r} g_{k}\left(V_{i}^{2}+V_{j}^{2}-2 V_{i} V_{j} \cos \theta_{i j}\right) \\
& F=P_{L}+\omega_{V} \times \text { Voltage Deviation }
\end{aligned}
$$


Voltage Deviation $=\sum_{\mathrm{i}=1}^{\mathrm{Npq}}\left|\mathrm{V}_{\mathrm{i}}-1\right|$

Constraint (Equality)

$$
P_{G}=P_{D}+P_{L}
$$

Constraints (Inequality)

$$
\begin{aligned}
& \mathrm{P}_{\text {gslack }}^{\min } \leq \mathrm{P}_{\text {gslack }} \leq \mathrm{P}_{\text {gslack }}^{\max } \\
& \mathrm{Q}_{\mathrm{gi}}^{\min } \leq \mathrm{Q}_{\mathrm{gi}} \leq \mathrm{Q}_{\mathrm{gi}}^{\max }, \mathrm{i} \in \mathrm{N}_{\mathrm{g}} \\
& \mathrm{V}_{\mathrm{i}}^{\min } \leq \mathrm{V}_{\mathrm{i}} \leq \mathrm{V}_{\mathrm{i}}^{\max }, \mathrm{i} \in \mathrm{N} \\
& \mathrm{T}_{\mathrm{i}}^{\min } \leq \mathrm{T}_{\mathrm{i}} \leq \mathrm{T}_{\mathrm{i}}^{\max }, \mathrm{i} \in \mathrm{N}_{\mathrm{T}} \\
& \mathrm{Q}_{\mathrm{c}}^{\min } \leq \mathrm{Q}_{\mathrm{c}} \leq \mathrm{Q}_{\mathrm{C}}^{\max }, \mathrm{i} \in \mathrm{N}_{\mathrm{C}}
\end{aligned}
$$

\section{ENHANCED WHALE OPTIMIZATION ALGORITH}

Projected algorithm has been modelled through Bubble-net hunting strategy of whale. Normally bubbles form a ' 9 -shaped path' through that whale encircle the prey during hunting. Whales normally move 10-16 meters down the sea then through the bubbles which created artificially in spiral shape by that it encircles the prey and move upward towards the surface of sea.

Encompassing prey equation after enclosing the prey whale evaluate its position,

$$
\begin{aligned}
& \vec{M}=|F \cdot \vec{Y} *(t)-Y(t)| \\
& \vec{Y}(t+1)=\vec{Y} *(t)-\vec{D} \cdot \vec{M} \\
& \vec{D}=2 \vec{k} * \text { random }-\vec{k} \\
& \vec{M}=2 * \text { random }
\end{aligned}
$$

Diminishing encircling method; it is done by reducing the value of ' $k$ ' from 2.0 to 0.0 . Then the capricious value of vector $\vec{D}$ will range from $[-1,1]$.

Modernization of spiral position; In this phase whale and prey position will be in helix-shaped then the movement is described by,

$$
\begin{aligned}
& \overrightarrow{\mathrm{Y}}(\mathrm{t}+1)=\overrightarrow{\mathrm{H}}^{\prime *} \mathrm{e}^{\mathrm{bt} *} \cos (2 \pi \mathrm{l})+\overrightarrow{\mathrm{Y}} *(\mathrm{t}) \\
& \overrightarrow{\mathrm{M}} \cdot=|\overrightarrow{\mathrm{Y}} *(\mathrm{t})-\mathrm{Y}(\mathrm{t})|
\end{aligned}
$$

In (15) describe the distance between " $\mathrm{i}$ " th whale to the prey and it point out the premium solution obtained so far. Movement of the whale in enclosed path or logarithmic path mode is described as,

$$
\overrightarrow{\mathrm{Y}}(\mathrm{t}+1)=\left\{\begin{array}{c}
\overrightarrow{\mathrm{Y}} * \overrightarrow{\mathrm{D}} \overrightarrow{\mathrm{M}} \text { if } \mathrm{p}<0.50 \\
\overrightarrow{\mathrm{M}}^{\prime *} \mathrm{e}^{\mathrm{bt} *} \cos (2 \pi \mathrm{l})+\overrightarrow{\mathrm{Y}} *(\mathrm{t}) \text { if } \mathrm{p} \geq 0.50
\end{array}\right.
$$

Prey exploration; $\vec{D}$ for prey exploration and value will be " 1 " or less than -1 . With reference to the condition's exploration is done in the search,

$$
\begin{aligned}
& \overrightarrow{\mathrm{M}}=\left|\overrightarrow{\mathrm{F}} \cdot \overrightarrow{\mathrm{X}_{\text {random }}}-\overrightarrow{\mathrm{Y}}\right| \\
& \mathrm{Y}(\mathrm{t}+1)=\overrightarrow{\mathrm{X}_{\text {random }}}-\overrightarrow{\mathrm{D}} \cdot \overrightarrow{\mathrm{M}}
\end{aligned}
$$


$|\overrightarrow{\mathrm{D}}|>1$; For finding the global optimum.

$|\overrightarrow{\mathrm{D}}|<1$; For updating the search agent position.

\section{ENHANCED WHALE OPTIMIZATION ALGORITHM}

An inertia weight $\omega \in[1,0]$ has been introduced in the whale optimization algorithm and by this modernized methodology surrounding of prey is defined by,

$$
\begin{aligned}
& \overrightarrow{\mathrm{M}}=\left|\overrightarrow{\mathrm{G}} \cdot \omega \overrightarrow{\mathrm{Y}}^{*}(\mathrm{t})-\overrightarrow{\mathrm{Y}}(\mathrm{t})\right| \\
& \overrightarrow{\mathrm{Y}}(\mathrm{t}+1)=\overrightarrow{\mathrm{Y}_{\text {random }}}-\overrightarrow{\mathrm{D}} \cdot \overrightarrow{\mathrm{M}}
\end{aligned}
$$

In phase of modernization of spiral position helix shaped sequence created by whale and described as:

$$
\begin{aligned}
& \vec{Y}(t+1)=\vec{M}^{\prime} * e^{b t *} \cos (2 \pi l)+\omega \vec{Y} *(t) \\
& M^{\prime}=\left|\omega Y^{*}(t)-Y(t)\right|
\end{aligned}
$$

Recoil circling produced by the whale is defined by,

$$
\overrightarrow{\mathrm{Y}}(\mathrm{t}+1)=\left\{\begin{array}{c}
\omega \overrightarrow{\mathrm{Y}} * \overrightarrow{\mathrm{H}} \overrightarrow{\mathrm{D}} \text { if } \mathrm{p}<0.50 \\
\overrightarrow{\mathrm{H}}^{\prime *} \mathrm{e}^{\mathrm{bt} *} \cos (2 \pi \mathrm{l})+\omega \overrightarrow{\mathrm{Y}} *(\mathrm{t}) \text { if } \mathrm{p} \geq 0.50
\end{array}\right.
$$

- Initialization of whale population

- Fitness of $\vec{Y}_{i}=(1,2, \ldots, n)$, is computed best $Y^{*}$. is found.

- Alter the exploration when $|\vec{D}|<1$ for every $\vec{Y}_{i}=(1,2, \ldots, n)$, and modernization of position is done by $\overrightarrow{\mathrm{M}}=\left|\overrightarrow{\mathrm{G}} . \omega \overrightarrow{\mathrm{Y}}^{*}(\mathrm{t})-\overrightarrow{\mathrm{Y}}(\mathrm{t})\right|$

- When $|\vec{B}|>1$, position modernizing is done by $Y(t+1)=\overrightarrow{Y_{\text {random }}}-\vec{D} \cdot \vec{M}$

- When $\mathrm{p} \geq 0.50$, modernize the position by, $\overrightarrow{\mathrm{Y}}(\mathrm{t}+1)=\overrightarrow{\mathrm{M}}^{\prime *} \mathrm{e}^{\mathrm{bt} *} \cos (2 \pi \mathrm{l})+\omega \overrightarrow{\mathrm{Y}} *(\mathrm{t})$

- Ensure if any explore agent goes away from the exploration and if so amend it.

- Calculate the fitness of $\vec{Y}_{i}=(1,2, \ldots, n)$, and find best $\vec{Y}^{*}$.

$-\mathrm{t}=\mathrm{t}+1$,

- Revisit the excellent solution $\overrightarrow{\mathrm{Y}}^{*}$ and premium fitness values.

\section{SIMULATION RESULTS}

Proposed enhanced Whale Optimization Algorithm (EWO) is tested in IEEE 57 Bus system [17]. Table 1 show control variables, Table 2 gives the reactive power generators, comparison of results is given in Table 3. Figure 1 shows the comparison of Real Power Loss and Figure 2 indicate about the Real power loss reduction in percentage.

Table 1. Constraints of control variables

\begin{tabular}{ccc}
\hline Parameter & Minimum value (PU) & Maximum value (PU) \\
Generator Voltage & 0.95 & 1.10 \\
Transformer Tap & 0.90 & 1.10 \\
VAR Source & 0.00 & 0.20 \\
\hline
\end{tabular}

Table 2. Constrains of reactive power generators

\begin{tabular}{ccc}
\hline BUS & Q Minimum $(\mathrm{PU})$ & Q Maximum $(\mathrm{PU})$ \\
\hline 1 & -140.00 & 200.00 \\
2 & -17.00 & 50.00 \\
3 & -10.00 & 60.00 \\
6 & -8.00 & 25.00 \\
8 & -140.00 & 200.00 \\
9 & -3.00 & 9.00 \\
12 & -150.00 & 155.00 \\
\hline
\end{tabular}


Table 3. Simulation results of IEEE -57 system

\begin{tabular}{|c|c|c|c|c|c|c|}
\hline Variable & Base case & MPSO [18] & PSO [18] & CGA [18] & AGA [18] & EWO \\
\hline VG 1 & 1.040 & 1.093 & 1.083 & 0.968 & 1.027 & 1.014 \\
\hline VG 2 & 1.010 & 1.086 & 1.071 & 1.049 & 1.011 & 1.013 \\
\hline VG 3 & 0.985 & 1.056 & 1.055 & 1.056 & 1.033 & 1.020 \\
\hline VG 6 & 0.980 & 1.038 & 1.036 & 0.987 & 1.001 & 1.012 \\
\hline VG 8 & 1.005 & 1.066 & 1.059 & 1.022 & 1.051 & 1.024 \\
\hline VG 9 & 0.980 & 1.054 & 1.048 & 0.991 & 1.051 & 1.021 \\
\hline VG 12 & 1.015 & 1.054 & 1.046 & 1.004 & 1.057 & 1.030 \\
\hline Tap 19 & 0.970 & 0.975 & 0.987 & 0.920 & 1.030 & 0.910 \\
\hline Tap 20 & 0.978 & 0.982 & 0.983 & 0.920 & 1.020 & 0.912 \\
\hline Tap 31 & 1.043 & 0.975 & 0.981 & 0.970 & 1.060 & 0.903 \\
\hline Tap 35 & 1.000 & 1.025 & 1.003 & $\mathrm{NR} *$ & $\mathrm{NR}^{*}$ & 1.002 \\
\hline Tap 36 & 1.000 & 1.002 & 0.985 & $\mathrm{NR}^{*}$ & $\mathrm{NR}^{*}$ & 1.014 \\
\hline Tap 37 & 1.043 & 1.007 & 1.009 & 0.900 & 0.990 & 1.011 \\
\hline Tap 41 & 0.967 & 0.994 & 1.007 & 0.910 & 1.100 & 0.910 \\
\hline Tap 46 & 0.975 & 1.013 & 1.018 & 1.100 & 0.980 & 1.022 \\
\hline Tap 54 & 0.955 & 0.988 & 0.986 & 0.940 & 1.010 & 0.934 \\
\hline Tap 58 & 0.955 & 0.979 & 0.992 & 0.950 & 1.080 & 0.923 \\
\hline Tap 59 & 0.900 & 0.983 & 0.990 & 1.030 & 0.940 & 0.941 \\
\hline Tap 65 & 0.930 & 1.015 & 0.997 & 1.090 & 0.950 & 1.055 \\
\hline Tap 66 & 0.895 & 0.975 & 0.984 & 0.900 & 1.050 & 0.914 \\
\hline Tap 71 & 0.958 & 1.020 & 0.990 & 0.900 & 0.950 & 1.024 \\
\hline Tap 73 & 0.958 & 1.001 & 0.988 & 1.000 & 1.010 & 1.023 \\
\hline Tap 76 & 0.980 & 0.979 & 0.980 & 0.960 & 0.940 & 0.930 \\
\hline Tap 80 & 0.940 & 1.002 & 1.017 & 1.000 & 1.000 & 1.012 \\
\hline QC 18 & 0.1 & 0.179 & 0.131 & 0.084 & 0.016 & 0.133 \\
\hline QC 25 & 0.059 & 0.176 & 0.144 & 0.008 & 0.015 & 0.142 \\
\hline QC 53 & 0.063 & 0.141 & 0.162 & 0.053 & 0.038 & 0.104 \\
\hline $\mathrm{PG}(\mathrm{MW})$ & 1278.6 & 1274.4 & 1274.8 & 1276 & 1275 & 1272.21 \\
\hline QC (Mvar) & 321.08 & 272.27 & 276.58 & 309.1 & 304.4 & 272.32 \\
\hline Reduction in PLoss (\%) & 0 & 15.4 & 14.1 & 9.2 & 11.6 & 23.93 \\
\hline Total PLoss (Mw) & 27.8 & 23.51 & 23.86 & 25.24 & 24.56 & 21.146 \\
\hline
\end{tabular}

NR* - Not reported

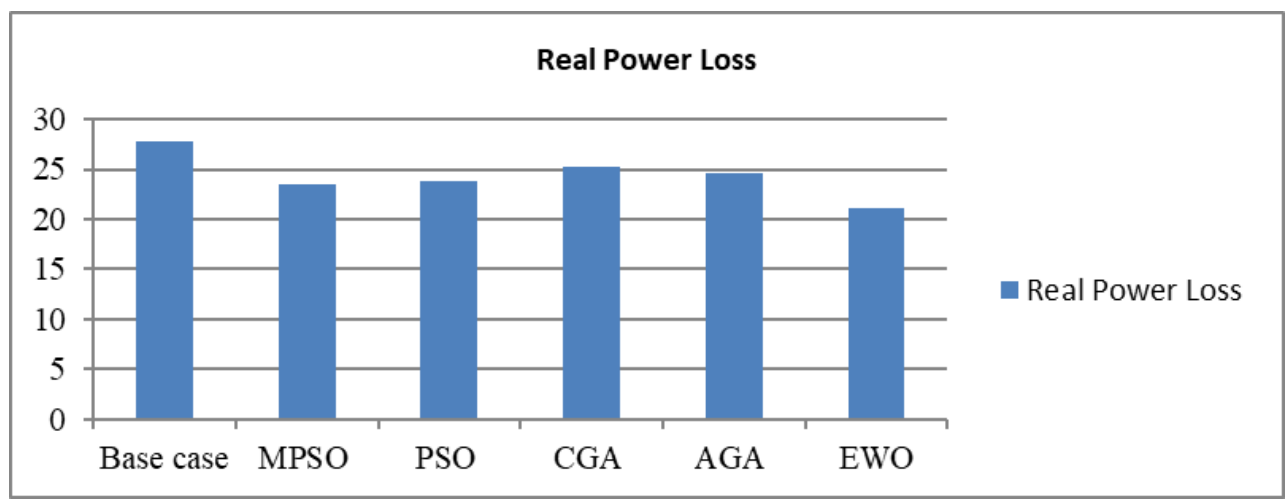

Figure 1. Comparison of real power loss

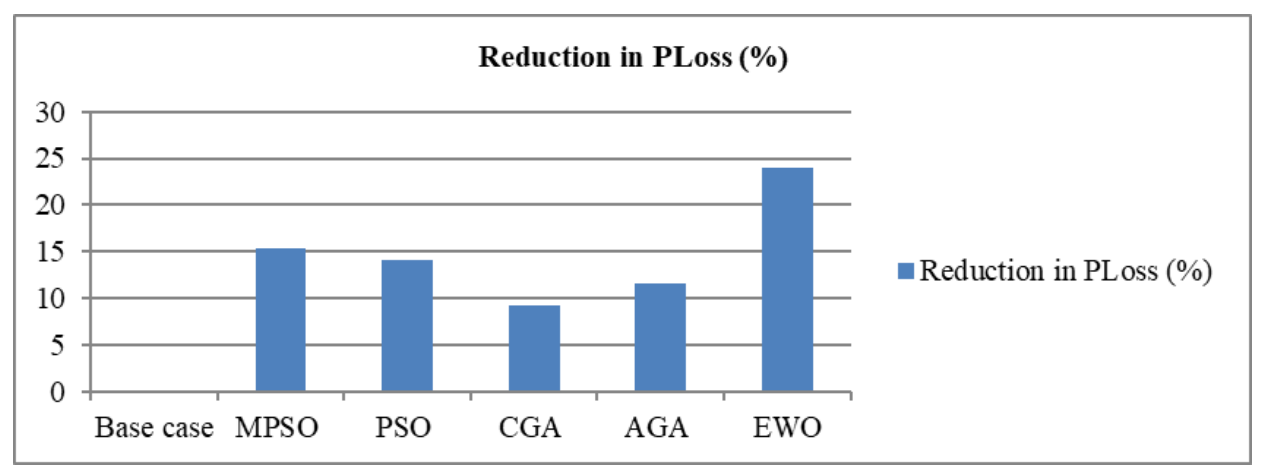

Figure 2. Real power loss reduction in percentage 


\section{CONCLUSION}

Enhanced whale Optimization Algorithm (EWO) solved the optimal reactive power problem efficiently. To pick up the pace of convergence during the period of exploration an inertia weight $\omega \in$ $[0,1]$ has been applied. Bubble-net hunting stratagem is used for modelling and most excellent candidate solution has been attained. In standard IEEE 57 bus test system Enhanced whale Optimization Algorithm (EWO) is tested and results shows that the projected algorithm reduced the real power loss efficiently. Reduction of real power loss value is $23.93 \%$ when compared to the base value.

\section{REFERENCES}

[1] K. Y. Lee "Fuel-cost minimisation for both real and reactive-power dispatches," Proceedings Generation, Transmission and Distribution Conference, vol. 131, pp. 3, pp. 85-93, 1984.

[2] N. I. Deeb, "An efficient technique for reactive power dispatch using a revised linear programming approach," Electric Power System Research, vol. 15, pp. 2, pp. 121-134, 1998.

[3] Shoults, R.R.; Sun, D.T., "Optimal power flow based upon P-Q decomposition," IEEE Transactions. Power Apparatus System, vol. 101, pp. 397-405, 1982.

[4] S. Granville. "Optimal reactive dispatch through interior point methods," IEEE Transactions on Power System, vol. 9, no. 1, pp. 136-146, 1994.

[5] N. Grudinin, "Reactive power optimization using successive quadratic programming method," IEEE Transactions on Power System, vol. 13, no. 4, pp. 1219-1225, 1998.

[6] T. Das and R. Roy, "Optimal reactive power dispatch using JAYA algorithm," 2018 Emerging Trends in Electronic Devices and Computational Techniques (EDCT), Kolkata, pp. 1-6, 2018.

[7] Y. Zhang, C. Chen and C. Lee, "Solution of the optimal reactive power dispatch for power systems by using novel charged system search algorithm," 2018 7th International Symposium on Next Generation Electronics (ISNE), Taipei, pp. 1-4, 2018.

[8] Roy, Provas Kumar and Susanta Dutta. "Economic Load Dispatch: Optimal Power Flow and Optimal Reactive Power Dispatch Concept." Optimal Power Flow Using Evolutionary Algorithms. IGI Global, pp. 46-64, 2019.

[9] Christian Bingane, Miguel F. Anjos, Sébastien Le Digabel, "Tight-and-cheap conic relaxation for the optimal reactive power dispatch problem", IEEE Transactions on Power Systems, 2019.

[10] D. Prasad and V. Mukherjee, "Solution of Optimal Reactive Power Dispatch by Symbiotic Organism Search Algorithm Incorporating FACTS Devices," IETE Journal of Research, vol. 64, no. 1, pp. 149-160, 2018.

[11] TM Aljohani, AF Ebrahim, O Mohammed, "Single and Multiobjective Optimal Reactive Power Dispatch Based on Hybrid Artificial Physics-Particle Swarm Optimization," Energies, vol. 12, no. 12, p. 2333, 2019.

[12] R. Kishan Mahate, Himmat S., "Multi-Objective Optimal Reactive Power Dispatch Using Differential Evolution," International Journal of Engineering Technologies and Management Research, vol. 6, no. 2, pp. 27-38, 2019.

[13] Yalçın, E, Taplamacioğlu, M, Çam, E., "The Adaptive Chaotic Symbiotic Organisms Search Algorithm Proposal for Optimal Reactive Power Dispatch Problem in Power Systems," Electrica 19. pp. 37-47, 2019.

[14] Mouassa, S. and Bouktir, T., "Multi-objective ant lion optimization algorithm to solve large-scale multi-objective optimal reactive power dispatch problem," COMPEL - The international journal for computation and mathematics in electrical and electronic engineering, vol. 38, pp. 1, pp. 304-324, 2019.

[15] Tawfiq M. Aljohani and Ahmed F. Ebrahim \& Osama Mohammed, "Single and Multiobjective Optimal Reactive Power Dispatch Based on Hybrid Artificial Physics-Particle Swarm Optimization," Energies, MDPI, vol. 12, no. 12, pp. 1-24, 2019.

[16] S. Mirjalili and A. Lewis, "The Whale Optimization Algorithm," Advances in Engineering Software, vol. 95, pp. 51-67, 2016.

[17] IEEE, "The IEEE-test systems", 1993. www.ee.washington.edu/trsearch/pstca/.

[18] Ali Nasser Hussain, Ali Abdulabbas Abdullah and Omar Muhammed Neda, "Modified Particle Swarm Optimization for Solution of Reactive Power Dispatch," Research Journal of Applied Sciences, Engineering and Technology, vol. 15, no.8, pp. 316-327, 2018. 